\title{
IOT-based Smart Bins
}

\author{
Sumit Parmar \\ Professor \\ Information Technology \\ Thakur Polytechnic Mumbai
}

\author{
Niyati Jain \\ Student \\ IF Semester VI \\ Thakur Polytechnic Mumbai
}

\author{
Saloni Negi \\ Student \\ IF Semester VI \\ Thakur Polytechnic Mumbai
}

\author{
Meera Prajapati \\ Student \\ IF Semester VI \\ Thakur Polytechnic Mumbai
}

\author{
Ishika Vaish \\ Student \\ IF Semester VI \\ Thakur Polytechnic Mumbai
}

\begin{abstract}
In this paper, we describe the formatting guidelines for IJCA Journal Submission Nowadays, waste management has become a major problem in life cycle. It includes the collection, transport, treatment and disposal of waste, together with monitoring and regulation of the waste management process. The significant cause of waste management is brisk growth in the rate of urbanization and thus there is a need of proper planning. To avoid all such harmful scenarios and maintain public cleanliness and health, we intend to propose a solution for this problem "Smart Bin" which will focus on resolving this problem. This process will alarm and notify the authorized person through a software when the garbage bin is about to fill. This system pivots around the overflowing bins and keeping the areas clean.
\end{abstract}

\section{Keywords}

Smart Bins, Internet of Things

\section{INTRODUCTION}

The current practice of waste disposal is unplanned and out of control due to lack of labor efforts of people working on the ground level emptying the garbage bins whenever they are full. The phenomenon of getting bins full is not fully dependent on a time pattern, instead it sometimes becomes abruptly full or sometimes requires more than normal time to become full. The detection, monitoring and management of waste is one of the key problems of the current era. The traditional way of manually examining the wastes in waste bins is an inconvenient process and utilize more labor work, time and cost which can easily be avoided with our present technologies. The idea struck us when we noticed that the garbage truck used to go around the town to collect solid waste twice a day.

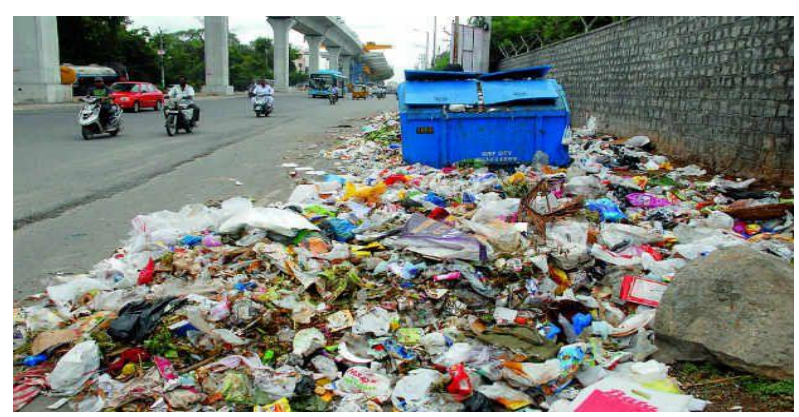

Fig. 1. Current Scenario
In order to have well planned and systematic structure, IOT has been merged with our lives. The Internet Of Things (IOT) is a system of physical things embedded with sensors, software, electronics and connectivity to allow it to perform better by communicating information with other connected devices. It allows us to use affordable wireless technology and transfer the data into the cloud at a component level. Whatever the future holds for IOT, smart device will become convoluted into our lives.

\section{PROPOSED SYSTEM}

In our proposed system, the level of garbage in the bins will be displayed to the authorized person so that the vehicles can be immediately driven towards that bin for clearance.

\subsection{Working}

IOT based Garbage Monitoring System will inform us whether the trash can is empty or full via IOT Gecko web development platform and you can know the status of your "Trash can". This proposed system uses ultrasonic sensors placed over the garbage bins to detect the garbage level and compare it with the garbage bin depth. This system makes use of AVR family microcontroller ,LCD screen, Wifi Modem and a buzzer. It is powered by $12 \mathrm{~V}$ transformer. LCD screen is used to show the status of the level of garbage collected in the bins. A particular limit is set i.e 5 units in the program code and if the garbage level exceeds it, system puts on the buzzer. Also the web page gives a visual view of the garbage bins and highlights the garbage collected in green color in order to show the proportion of garbage collected.

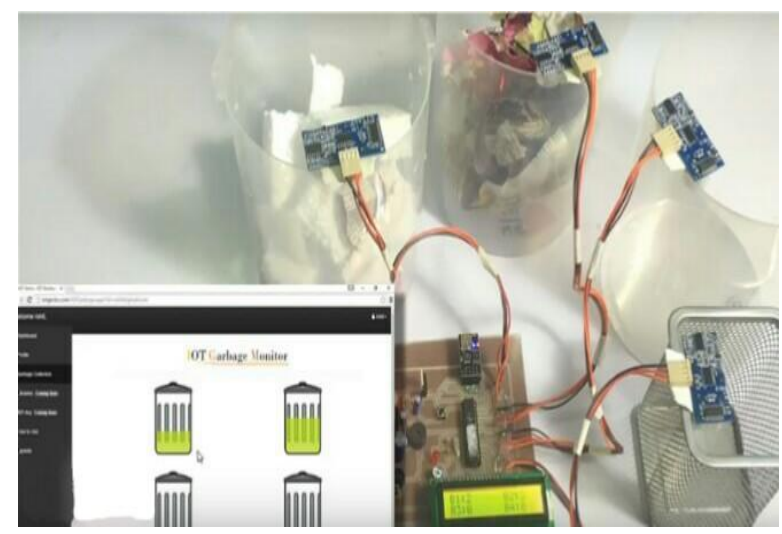

Fig 2. Working Of The System. 


\subsection{Components}

\subsubsection{Hardware specifications -}

\subsubsection{Atmega Microcontroller :}

We have used Arduino UNO for connecting all the sensors through pins. In the AVR microcontroller the code and the data will be stored in separate physical memory in different address spaces.

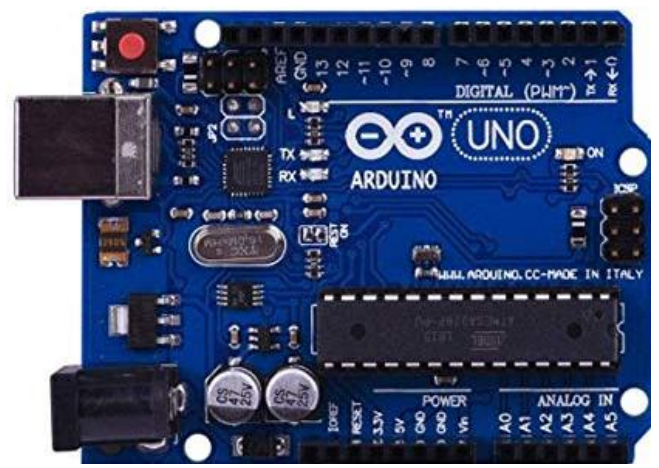

Fig 3. Arduino UNO

\subsubsection{Ultrasonic sensor:}

The Ultrasonic sensor is used for calculating the level of garbage filled in the bin. There are two opening in the sensor. One transmits the ultrasonic waves and the other one receives the wave. The wave emitted by the sensor travels in air and when it hits any material, it gets reflected back toward the sensor. This reflected wave is observed by the receiver module and calculates the level by calculating the time taken by the wave to retransmit back at the receiver side.

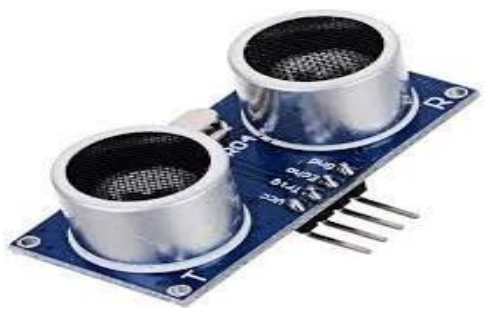

Fig 4. Ultrasonic Sensor

\subsubsection{ESP8266 Wifi Module:}

Wi-Fi Module helps us to send the data of the bin at the other side. The ESP8266 is a inexpensive Wi-Fi microchip with full TCP/IP stack and microcontroller capability. The ESP8266 WiFi Module is a self contained SOC which gives a microcontroller access to the WiFi network.

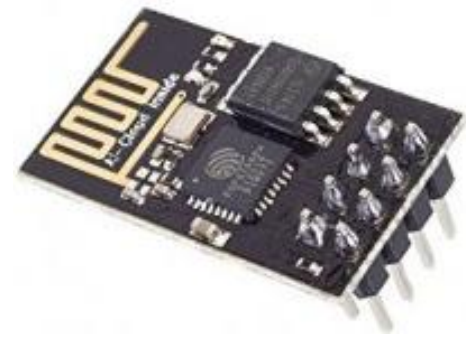

Fig 5. ESP8266 Wifi Module

\subsubsection{Software specification-}

\subsubsection{Arduino Compiler:}

It is an open-source Arduino Software (IDE) which is simple to understand, write code and upload it to the board. It gives a user friendly and understanding platform for the coders to write code. It supports java language. We have written the code for garbage collection in the Arduino IDE software.

\subsubsection{IOT Gecko :}

IOT Gecko is a free IOT systems development platform for students, researchers as well as developers. IOT Gecko provides the tools required. It is a supportive software to design your IOT based systems with ease.

\subsubsection{MC Programming Language: $C$}

\section{FLOW CHART}

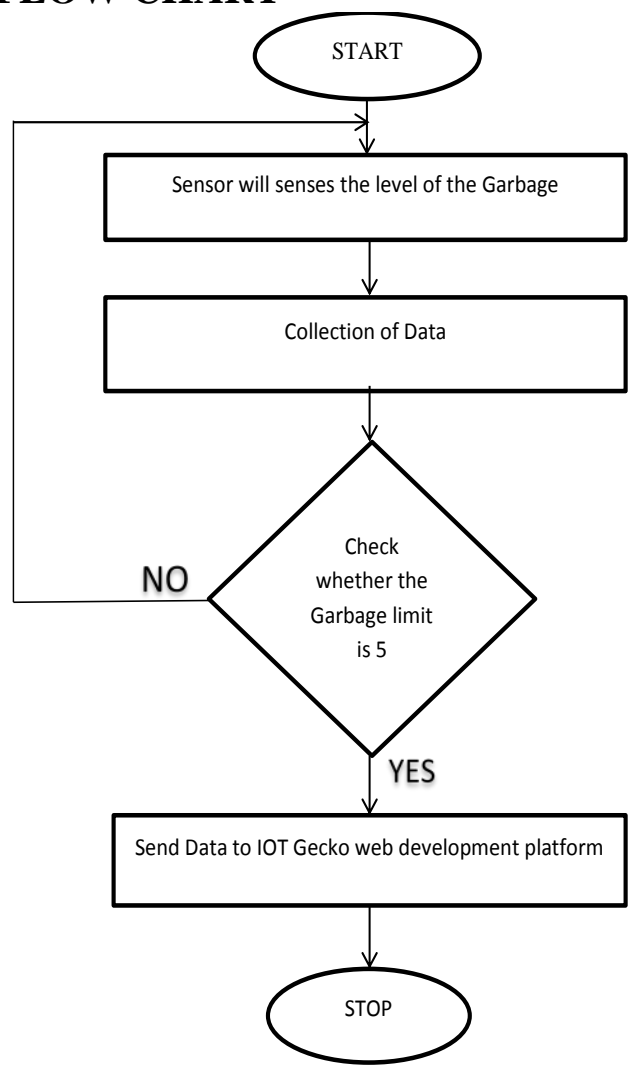

\section{BLOCK DIAGRAM}

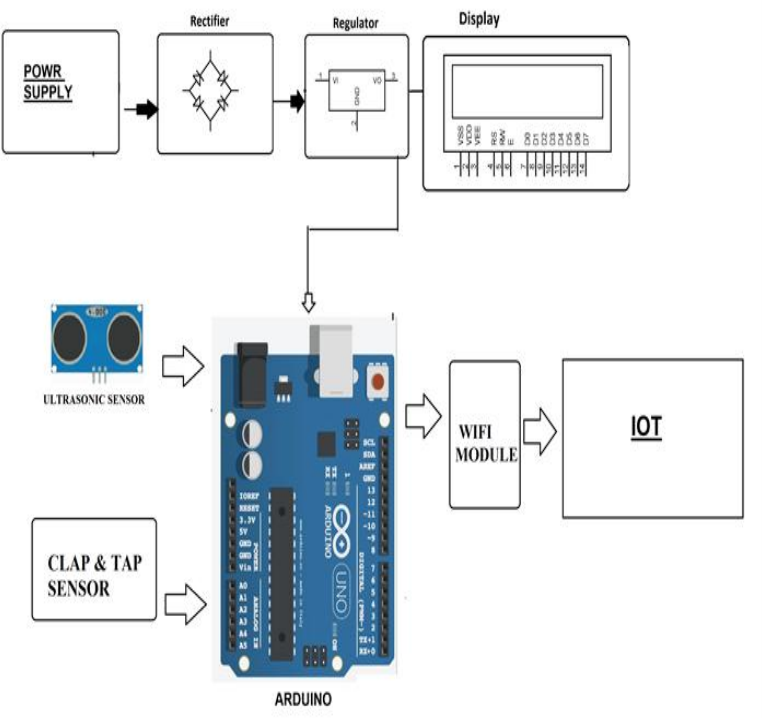




\section{APPLICATION}

- Avoids the overloading of garbage bins.

- Waste collection would become efficient and also cutback in transportation costs can be observed.

- It is a system which will help to keep the cities clean.

- Empowerment of "SWACHH BHARAT ABHIYAN"

- This project can only be used by municipal authorities or other private firms to handle the current problem of urban waste collection.

\section{CONCLUSION AND FUTURE SCOPE}

Thus we conclude that this system guarantees the cleaning of dustbins soon when the garbage level reaches its maximum. The main goal of this proposed system is to keep cleanliness in city and to form an environment which is healthier for living. With the help of this system, we can constantly keep a track of level of garbage in the bins.
Through IOT Gecko web development platform, employees can monitor the status of the bins of a particular area. This is an ideal project for people who are willing to take one step further for increasing the cleanliness in their respected areas. This minimizes manual work by examining which bin is filled on screen rather than roaming from one area to another. Now this system can be used in certain areas but as soon as it proves its reliability, it can be used in all the big areas. In future, government authorities can handle and maintain this system for developing a Smart City.

\section{REFERENCES}

[1] Anjali V. Tarone, "IOT Based Smart Garbage Monitoring System Using ESP8266 with GPS Link," International Research Journal of Engineering and Technology (IRJET), vol. 05, Issue: 03 | Mar-2018.

[2] Sapna Suryawanshi, "Waste Management System Based On IoT," International Research Journal of Engineering and Technology (IRJET), vol. 05, Issue: 03 | Mar-2 